- In a random population sample of adults, one in six people reported impacts 'fairly often' or 'very often' during the preceding year.

- There was striking similarity in the prevalence of problems in everyday life attributed to oral disorders in the UK and Australia.

- Differences were observed in individual impacts, with Australians more likely to report four items categorised as pain and physical disability.

- Dentate Australians tended to report a larger number of impacts occurring at low frequency than dentate people in the UK.

- Population differences in the impact of oral disorders may be an artifact of different collection methods or may reflect subtle sociocultural differences in subjective oral health.

\title{
Impacts of oral disorders in the United Kingdom and Australia
}

\author{
G. D. Slade, ${ }^{1}$ N. Nuttall, ${ }^{2}$ A. E. Sanders, ${ }^{3}$ J. G. Steele, ${ }^{4}$ P. F. Allen ${ }^{5}$ and S. Lahti 6
}

\begin{abstract}
Background Surveys of oral health have not previously compared national adult populations using measures of subjective oral health. Aims To compare subjective oral health of adults in the UK and Australian populations.
\end{abstract}

Methods Cross sectional studies were conducted of people aged 18+ years in the 1998 UK Adult Dental Health Survey and the 1999 Australian National Dental Telephone Interview Survey. Subjective oral health was measured using the 14-item Oral Health Impact Profile questionnaire (OHIP-14).

Results Among dentate people, the percentage reporting impacts 'fairly often' or 'very often' was marginally greater in Australia (18.2\%, 95\% confidence interval $(\mathrm{Cl})=16.2-20.2)$ than the UK $(15.9 \%, 95 \% \mathrm{Cl}=$ 14.4-17.4). There were larger regional variations in prevalence within populations, ranging from $14.8 \%$ to $22.3 \%$ among Australian states/ territories, and from $13.6 \%$ to $19.8 \%$ among countries within the UK. However, the mean number of impacts and rated severity of impacts was significantly greater in Australia than the UK.

Conclusions While the percentage of adults reporting adverse impacts of oral health was similar, Australians reported a larger number of impacts and more severe impacts than dentate people in the UK. Differences in the number and severity of impacts between the two populations may be an artifact of different data collection methods or may reflect relatively subtle socio-cultural differences in subjective oral health between these populations.

\section{INTRODUCTION}

National population surveys have been used to monitor oral health status in many countries and ideally they contribute to identification of health goals, development of health policy and evaluation of health programmes. Data typically collected in such surveys include clinical signs of dental caries, condition of existing restorations, periodontal health indices, presence and condition of dentures and soft tissue pathology. ${ }^{1}$ However, clinical signs of disease represent only one aspect of overall health, and increasingly researchers have begun to include subjective evaluations of function and well-being when describing the health of patients or populations. ${ }^{2}$ This is in keeping with a theoretical concept of health that differs from a traditional biomedical model of health and disease that focuses solely on clinical conditions. ${ }^{3}$

A growing emphasis on subjective health status and quality of life is also reflected in national health policies. One objective of Australia's National Health Priority Action Council is to 'increase the proportion of Australians with chronic illness who report a satisfactory level of health-related quality of life. ${ }^{4}$ In developing its national health goals for 2010, the US Department of Health and Human Services ${ }^{5}$ declared, 'The first goal of Healthy People 2010 is to help individuals of all ages increase life expectancy and improve their quality of life.' Until recently, however, population assessment of subjective oral health status has been limited to single questions that vary between studies. For example, the third US National Health and Nutrition Examination Survey asked respondents 'How would you describe the condition of your natural teeth?' while the second International Collaborative Study ${ }^{6}$ asked participants in six countries 'How would you describe the health of your teeth and gums?'

More detailed assessments of oral health related quality of life (OHRQoL) evaluate several dimensions of subjective well-being, including the effects of oral conditions on oro-facial pain, function (including eating), sleeping and psychosocial well-being. ${ }^{7}$ McGrath and $\mathrm{Bedi}^{8}$ administered the 16 -item UK Oral Health Related Quality of Life measure (OHQoL-UK) in a face-to-face interview survey of a random sample of adults representative of the British population. Seventy-five per cent of respondents reported that oral health affected their quality of life, either in a negative or positive manner, or both. However, no published studies have compared subjective oral health status in national 


\begin{tabular}{|c|c|c|}
\hline & United Kingdom & Australia \\
\hline Year & 1998 & 1999 \\
\hline \multirow[t]{2}{*}{ No. of subjects* } & 5,270 & 3,909 \\
\hline & $\%$ of people & \% of people \\
\hline \multicolumn{2}{|l|}{ Age: } & 51 \\
\hline $18-<30$ yrs & 25 & 24 \\
\hline $30-39$ yrs & 24 & 21 \\
\hline $40-49$ yrs & 19 & 19 \\
\hline $50-59$ yrs & 15 & 15 \\
\hline $60-69$ yrs & 10 & 10 \\
\hline $70+y r s$ & 7 & 11 \\
\hline Edentulous & 0 & 7 \\
\hline
\end{tabular}

population samples using a comprehensive, standardised questionnaire. The aims of this study were:

- To describe adverse impacts of oral disorders among adults in the populations of Australia and the United Kingdom using the 14-item Oral Health Impact Profile questionnaire (OHIP-14) ${ }^{9}$ and to provide population norms for both countries.

- To describe similarities and differences in impacts, and to identify impacts that contribute most to variations in subjective oral health.

Australia and the United Kingdom represent two populations that share a common historical and cultural heritage, although there are some important differences in oral health status and the organisation of dental services. Nonetheless, based on our preceding review of the literature, we hypothesised that oral health impacts in the current study would be similar in the two populations.

\section{METHODS}

The data were from two national surveys of oral health that used the OHIP-14. Each study was reviewed and approved by ethics committees in the respective country. The first study was the 1998 UK Adult Dental Health Survey where face-to-face interviews were conducted, including an interviewer-administered OHIP-14 questionnaire. Subjects were a representative probability sample of residents in England, Scotland, Wales and Northern Ireland. Some 5,270 dentate adults aged 16+ yrs were interviewed, representing a response rate of $72 \%$ among eligible subjects sampled for the survey. ${ }^{10}$

The second study was the 1999 National Dental Telephone Interview Survey (NDTIS) conducted in Australia. ${ }^{11}$ Using a stratified random sampling design for all states and territories, the NDTIS collected data on self-reported oral health and use of dental services from 7,829 people aged five years and over. Immediately following the interview, a mail survey was sent to all dentate and edentulous adult interviewees $(n=6,150)$. This survey included questions measuring psychosocial and behavioural factors as well as the 14-item Oral Health Impact Profile. Overall 3,973 adults returned the questionnaire (response rate $=64.6 \%$ ). A comparison of the socio-demographic characteristics of responders and nonresponders to the mail survey in Australia revealed significantly lower response ( $\mathrm{p}<0.05$, Chi-square) from males, young adults, capital city dwellers, and the socio-economically disadvantaged. Differences based on country of birth (Australia or other) were not significant.

The 14-item Oral Health Impact Profile used in both populations, contains 14 questions that ask about the frequency of adverse impacts caused by oral conditions during the previous 12 months. ${ }^{9}$ For example, subjects were asked, 'How often during the past year have you had painful aching in your mouth because of problems with your teeth, mouth or dentures?' Respondents answered on a five-point ordinal scale ranging from 'very often' to 'never'. Questions in the OHIP-14 encompass seven conceptual dimensions, two questions per dimension, that capture a conceptual model of oral health adapted by Locker ${ }^{3}$ from the 1980 World Health Organisation International Classification of Impairments, Disabilities and Handicaps (ICIDH). ${ }^{12}$ The dimensions are: functional limitation, physical pain, psychological discomfort, physical disability, psychological disability, social disability and handicap. These represent a hierarchy of impacts that increasingly impinge on broader aspects everyday life.

In the UK, a trained interviewer administered the OHIP-14 questionnaire to dentate adults only, whereas in Australia it was self-administered and completed by dentate and edentulous adults. For this analysis, ordinal values were coded for each question ranging from zero for a response of 'never' through to four for a response of 'very often'. Three summary variables were then computed:

- Prevalence: is the percentage of people reporting one or more items 'fairly often' or 'very often'.

- Extent: is the number of items reported 'fairly often' or 'very often'.

- Severity is the sum of ordinal responses: hence, it additionally takes into account impacts experienced occasionally or hardly ever, and could range from 0 to 56 .

The threshold for defining prevalence and extent is consistent with previously established summary statistics for the OHIP-49 questionnaire. ${ }^{13}$ The 'severity' measure, by using all response categories, attempts to overcome limitations that may be inherent in restricting summary scores to the arbitrary threshold of impacts occurring ‘fairly often' or 'very often'. When computing OHIP summary scores, subjects with missing values to more than two OHIP items (due to non-response or answering ‘don't know') were eliminated from the analysis. When computing severity scores for other subjects, any missing values for an OHIP item were replaced with the sample mean computed from non-missing responses to the relevant OHIP item. The data were also re-analysed excluding subjects with any missing items, although mean scores changed by no more than one decimal place, and those results are not reported below.

This paper presents descriptive statistics for adults aged 18+ years in each population, stratified by dentition status (dentate versus edentulous) within Australia. In order to produce results that could be generalised to the adult populations of each popula-

\begin{tabular}{|c|c|c|c|}
\hline & \multicolumn{3}{|c|}{ Estimate $(95 \% \mathrm{Cl})$ for: } \\
\hline & UK dentate & AU dentate & $\mathrm{AU}$ edentulous ${ }^{(\mathrm{a})}$ \\
\hline \multicolumn{4}{|l|}{ Prevalence: } \\
\hline Prevalence: \% of people reporting $1+$ impacts fairly/very often & $15.9(14.9-16.8)$ & $18.2(16.2-20.2)$ & $23.9(18.2-29.6)$ \\
\hline Extent: mean no. of items reported fairly/very often (extent) & $0.36(0.32-0.40)$ & $0.46(0.39-0.52)$ & $0.72(0.46-0.97)$ \\
\hline Severity: mean OHIP-14 score & $5.1(4.8-5.3)$ & $7.5(7.1-7.9)$ & $9.3(7.9-10.6)$ \\
\hline
\end{tabular}




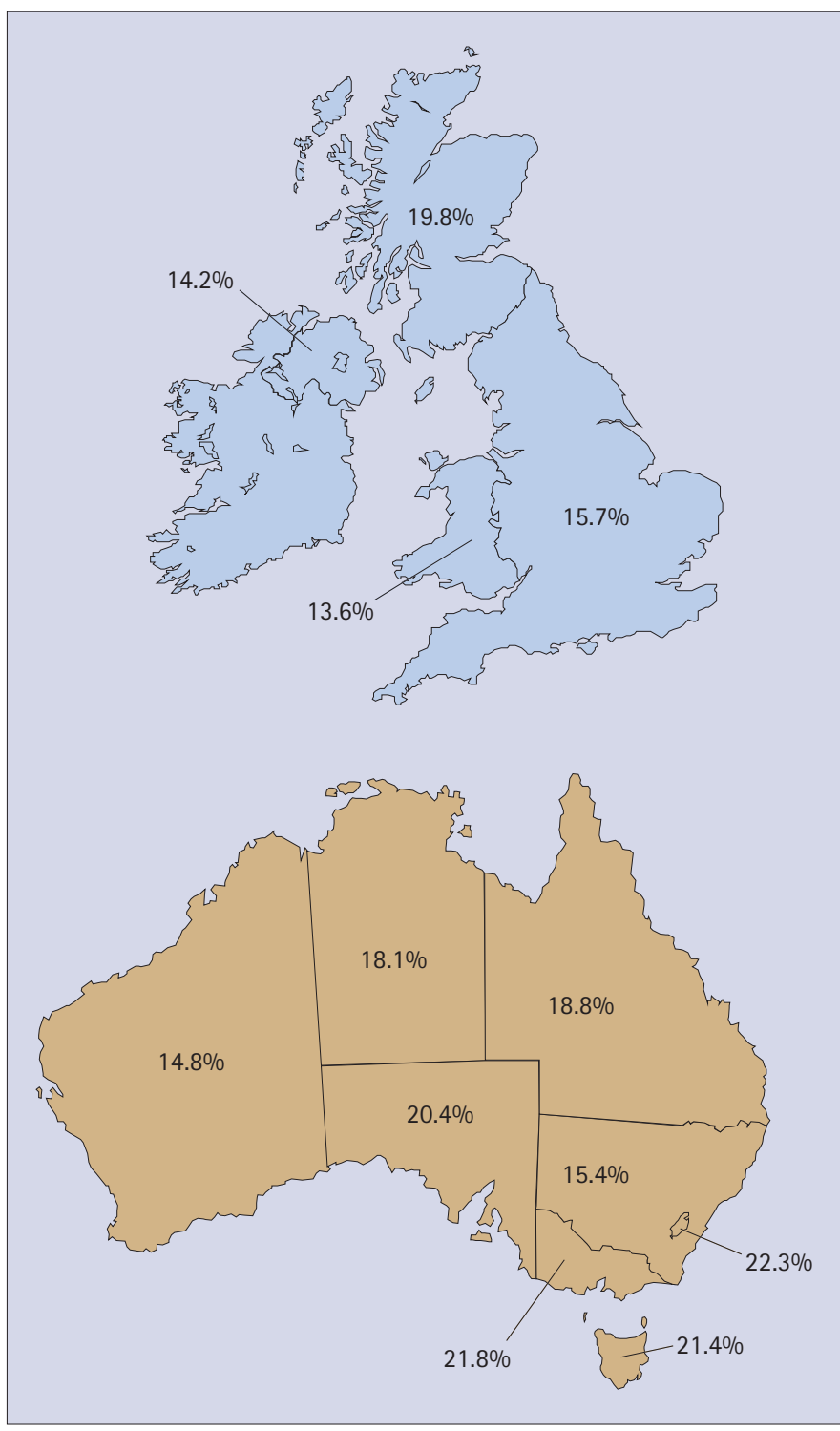

Fig. 1 Regional distribution of prevalence of reported impacts among dentate people. Percentage of dentate people reporting one or more impacts 'fairly often' or 'very often', UK 1998 and Australia 1999 ( $n=3,003$ in England, 680 in Wales, 952 in Scotland, 634 in Northern Ireland, 527 in New South Wales, 519 in Victoria, 554 in Queensland, 542 in South Australia, 543 in Western Australia).

tion, we computed weighted estimates of prevalence, extent and severity for all results other than response rates. Data were weighted to the age and sex structure of the estimated resident populations in each sampling region, thus correcting for the small differences in participation rates observed between sexes, among age groups and among geographic localities. When computing 95\% confidence intervals for the UK, we increased our computed standard error (se) by the square root of 1.6 , where 1.6 was the published sampling design effect ${ }^{10}$ (Table F.28 of Ref. 10). For the stratified sampling scheme in Australia, we analysed data using SUDAAN software to compute standard errors that adjusted for the stratified sampling design.

\section{RESULTS}

The sex- and age-category distributions of the UK and Australian samples differed by no more than four percentage points (Table 1). Unlike the UK sample, where edentulous subjects were excluded, 7\% of Australians were edentulous. More detailed descriptive statistics for each population have been pro-

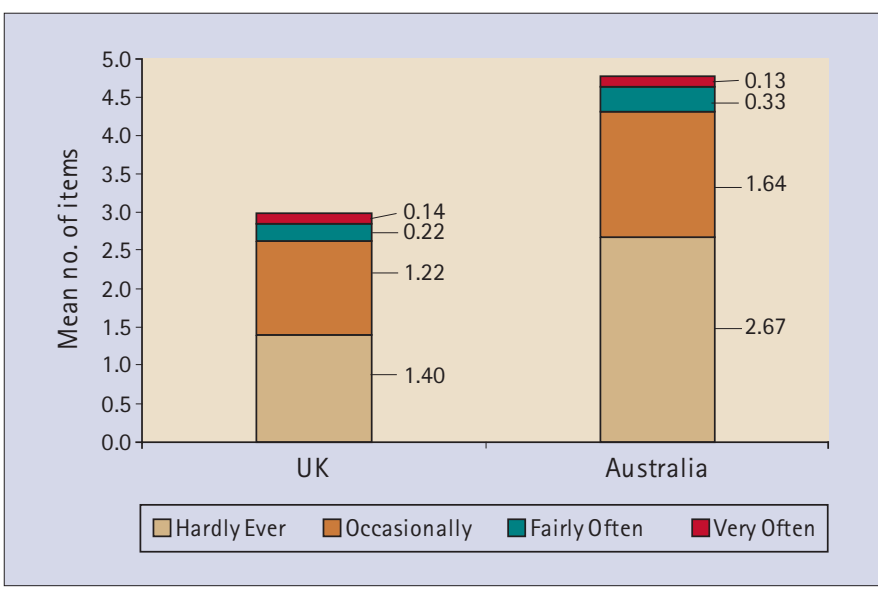

Fig. 2 Number of items reported at four levels of frequency - dentate people

vided elsewhere. ${ }^{10,11}$ Among dentate people, the prevalence of impacts was greater in Australia (18.2\%) than the UK (15.9\%), although the 95\% confidence intervals overlapped (Table 2). In contrast, among Australians, prevalence was five percentage points greater for edentulous compared with dentate people, a relative difference of approximately one third.

Differences in prevalence between Australia and the UK were much smaller than regional variation within those populations. For example among Australian states, prevalence varied from 14.8\% (Western Australia) to 22.3\% (Australian Capital Territory) while within the UK, prevalence ranged from 13.6\% (Wales) to 19.8\% (Scotland) (Fig. 1).

Differences in impact between dentate UK and dentate Australian groups were more pronounced when extent and severity scores were contrasted. In Australia, the extent score of 0.46 was approximately one quarter greater than the UK figure of 0.36 , while the Australian severity score of 7.5 was approximately one half greater than the figure of 5.1 for the UK. Ninety-five per cent confidence intervals for severity did not overlap between Australia and the UK. Compared with the Australian dentate, the Australian edentulous experienced significantly greater extent and severity of impact yet the difference in severity scores between dentate and edentulous Australians was not as large as the difference in severity scores between dentate UK and dentate Australians (Table 2).

Figure 2 demonstrates that dentate people in Australia and the UK differed most conspicuously for items reported below the threshold of 'fairly often'. For example, an average of 2.67 items were reported 'hardly ever' in Australia, compared with only 1.40 items in the UK. In contrast, the mean number of items reported 'very often' was almost identical: 0.14 in Australia and 0.13 in the UK.

Variations between populations were most apparent when two selected dimensions of the OHIP ${ }^{14}$ were grouped (Table 3). Severity scores, summed for the four items in the physical pain and physical disability dimensions accounted for an absolute difference of 1.3

\begin{tabular}{|c|c|c|c|c|c|}
\hline & \multicolumn{4}{|c|}{ Severity of impacts } & \multirow{3}{*}{$\%$} \\
\hline & \multirow{2}{*}{$\begin{array}{l}\text { No. of } \\
\text { items }\end{array}$} & \multicolumn{2}{|c|}{ (mean 95\% Cl) } & \multirow{2}{*}{$\begin{array}{l}\text { Difference } \\
\text { (AU vs UK) }\end{array}$} & \\
\hline & & UK & $\mathrm{AU}$ & & \\
\hline $\begin{array}{l}\text { Physical pain/ } \\
\text { physical disability }\end{array}$ & 4 & $2.1(2.0-2.2)$ & $3.4(3.3-3.6)$ & 1.3 & $+62 \%$ \\
\hline Other dimensions & 10 & $2.9(2.8-3.1)$ & $4.0(3.8-4.3)$ & 1.1 & $+37 \%$ \\
\hline All OHIP items & 14 & $5.1(4.8-5.3)$ & $7.5(7.1-7.9)$ & 2.4 & $+48 \%$ \\
\hline
\end{tabular}




\begin{tabular}{llccc}
\multicolumn{5}{l}{ Table 4 Severity of individual impacts - dentate people } \\
\hline
\end{tabular}

in severity scores between populations, a relative difference of $62 \%$. However, the remaining ten OHIP items accounted for a difference of only 1.1 in severity scores, and a relative difference of $37 \%$. The four items therefore accounted for more than half of the difference in severity observed between the countries.

While the overall severity of impacts among dentate people was greater in Australia compared with the UK, relative differences between the populations varied among specific OHIP items (Table 4). Mean severity scores for four items differed by less than one quarter between the two populations ('Being self-conscious', 'Feeling tense', 'Life less satisfying' and 'Been a bit irritable') while there was a two-fold difference in four other items ('Difficulty doing jobs', 'Unable to function', 'Trouble pronouncing words' and 'Diet unsatisfactory').

To enable comparisons with future studies, the Appendix presents the distribution of OHIP-14 severity scores including the means, standard deviations and selected percentile values for dentate people in the UK and Australia.

\section{DISCUSSION}

The percentage of dentate people reporting impacts 'fairly often' or 'very often' was strikingly similar in the UK and Australia. Our interpretation of equivalence is based on the degree of overlap in 95\% confidence intervals for prevalence (Table 2) and the finding that prevalence differed by only $2.3 \%$ between dentate people in the UK and Australia, considerably smaller than the 5.7\% difference between dentate and edentulous Australians. However, dentate people in the two populations differed in subtle respects which became apparent when comparisons were made using summary scores that considered impacts occurring 'hardly ever' or 'occasionally', and that took into account the number of impacts experienced. Dentate Australians tended to report a larger number of impacts occurring at low frequency than dentate people in the UK (see Figure 2). Furthermore, most of the difference between the populations was due to four items categorised as pain and physical disability. It is worth noting though that the differences between regions of both the UK and Australia were considerably greater than the differences between the countries themselves.

These results are based on representative population samples of adults aged 18+ years in both populations, and the large sample sizes preclude the possibility that low statistical power could have contributed to a lack of difference in prevalence between the two populations. However, there were other methodological issues which merit consideration. One was the potential effect of differences in data collection methodology: self-completed questionnaires were used in Australia, compared with interviewer-admin- istered interviews in the UK. In a study of dental patients in the UK, Robinson et al. ${ }^{14}$ compared randomly-assigned interview and selfcompleted versions of the OHIP-14 and found that the number of items reported 'occasionally' or more often was only slightly higher for the self-complete format (mean $\pm \mathrm{se}=8.5 \pm 4.3$ ) than for the interview format $(7.1 \pm 7.2)$. This suggests that the small observed differences in severity scores in the current study might be due partly to different methods of administering the OHIP, and confirms our overall impression that levels of impact in the two populations were very similar. A second issue is potential bias due to non-participation in each of the population studies. However such biases should be minimised, both because of the weighting schemes, that adjusted the sample to be representative of the national populations, and because factors contributing to nonparticipation probably were similar in both Australia and the UK.

Substantial majorities of subjects in both populations reported no impacts, indicating a large 'floor effect' of impacts measured using the OHIP-14. In addition, mean severity scores were low in both populations, given their potential range from zero to 56 . These findings signify that the content of the OHIP-14 is dominated by relatively severe impacts on daily life, which is consistent with its theoretical basis in the ICDH. OHIP-14 investigates all seven dimensions of impact identified in Locker's adaptation of the ICIDH framework ${ }^{3}$ that are arranged in ascending hierarchical order from functional limitation to handicap. In general population samples, relatively few people are handicapped or experience the more severe dimensions of disability represented in the model. While it may be argued that OHIP-14 is not sensitive to minor impacts occurring outside the parameters of ICDH framework, it is unlikely that these minor impacts would be accorded high priority from a public health perspective. Of note, considerably higher rates of prevalence and severity than those investigated in this study from random population samples were found using the OHIP-14 scale with a UK sample of dental patients. ${ }^{15}$

While this study is the first to compare subjective oral health in nationally representative samples of adults aged 18 years and over using a multiple-item questionnaire, there are consistencies with results from a study of adults aged 65+ years in regions of South Australia, Ontario and the North Carolina. ${ }^{13}$ In that study, smaller differences were observed between countries than between racial groups within countries. In the second International Collaborative Study that used a global self rating or oral health, ${ }^{6}$ there were relatively small differences between English-speaking, majority populations in western countries: for example, in New Zealand, 7\% of 35-44 year olds reported 'poor' or 'very poor' oral health compared with $8 \%$ in Baltimore, USA. Our finding that edentulous Australians reported higher levels of impact than dentate Australians is consistent with numerous previous cross-sectional studies of smaller, selected samples. ${ }^{16-18}$

At first appearance, the prevalence of impacts in this study was substantially lower than the finding, reported by McGrath and Bedi $^{8}$ that $75 \%$ of people in the British population perceived oral health as affecting their life quality. However, there are important conceptual and methodological differences in the ways that these two studies measured quality of life. The OHQoL-UK ${ }^{8}$ captures perceptions about both positive and negative impacts on oral health, whereas the OHIP-14 captures only negative impacts. Furthermore, McGrath and Bedi ${ }^{8}$ included all perceptions regardless of their frequency, whereas in the current study a threshold was applied that limited analysis to those impacts reported 'fairly often' or 'very often' in the previous year. While our study therefore underestimates the total impact of oral conditions, we have adopted this more-restrictive definition of prevalence of adverse impacts in order to compare aspects of OHRQoL that, because of their chronic or repeated nature, are likely to be important from a public health perspective. 


\begin{tabular}{|c|c|c|c|c|c|c|c|c|}
\hline \multirow{2}{*}{$\begin{array}{l}\text { United Kingdom } \\
\text { Age }\end{array}$} & \multirow[b]{2}{*}{ Sex } & \multirow[b]{2}{*}{ Mean } & \multirow[b]{2}{*}{ sd } & \multicolumn{5}{|c|}{ Percentiles } \\
\hline & & & & 10th & 25th & 50th & 75th & 90th \\
\hline \multirow[t]{2}{*}{$18-24$ yrs } & Male & 5.9 & 7.6 & 0.0 & 1.0 & 4.0 & 8.0 & 13.0 \\
\hline & Female & 5.2 & 7.6 & 0.0 & 0.0 & 2.0 & 7.0 & 15.0 \\
\hline \multirow[t]{2}{*}{$25-34$ yrs } & Male & 5.1 & 6.7 & 0.0 & 1.0 & 3.0 & 7.0 & 14.0 \\
\hline & Female & 5.3 & 6.2 & 0.0 & 0.0 & 3.0 & 8.0 & 15.0 \\
\hline \multirow[t]{2}{*}{$35-44$ yrs } & Male & 4.4 & 6.0 & 0.0 & 0.0 & 2.0 & 6.0 & 11.0 \\
\hline & Female & 5.9 & 7.0 & 0.0 & 0.0 & 3.0 & 9.0 & 16.0 \\
\hline \multirow[t]{2}{*}{$45-54$ yrs } & Male & 5.3 & 6.3 & 0.0 & 0.0 & 3.0 & 8.0 & 14.0 \\
\hline & Female & 6.1 & 7.2 & 0.0 & 0.0 & 3.0 & 9.0 & 17.0 \\
\hline \multirow[t]{2}{*}{$55-64$ yrs } & Male & 4.4 & 6.1 & 0.0 & 0.0 & 2.0 & 6.0 & 13.0 \\
\hline & Female & 5.0 & 6.0 & 0.0 & 0.0 & 3.0 & 7.0 & 13.0 \\
\hline \multirow[t]{2}{*}{$65+y r s$} & Male & 3.6 & 5.3 & 0.0 & 0.0 & 2.0 & 5.0 & 11.0 \\
\hline & Female & 3.7 & 6.8 & 0.0 & 0.0 & 1.0 & 4.0 & 10.0 \\
\hline \multicolumn{2}{|l|}{ Australia } & & & \multicolumn{5}{|c|}{ Percentiles } \\
\hline Age & Sex & Mean & sd & 10th & 25 th & 50th & 75th & 90th \\
\hline \multirow[t]{2}{*}{$18-24$ yrs } & Male & 6.3 & 10.5 & 0.0 & 2.0 & 4.0 & 9.0 & 17.0 \\
\hline & Female & 6.7 & 7.9 & 1.0 & 3.0 & 5.0 & 9.0 & 15.0 \\
\hline \multirow[t]{2}{*}{$25-34$ yrs } & Male & 6.9 & 10.4 & 0.0 & 1.0 & 4.0 & 12.0 & 18.0 \\
\hline & Female & 7.9 & 8.4 & 0.0 & 2.0 & 5.0 & 12.0 & 19.0 \\
\hline \multirow[t]{2}{*}{$35-44$ yrs } & Male & 7.9 & 9.2 & 1.0 & 2.0 & 5.2 & 11.0 & 20.5 \\
\hline & Female & 8.4 & 7.8 & 1.0 & 3.0 & 6.0 & 11.0 & 18.0 \\
\hline \multirow[t]{2}{*}{$45-54$ yrs } & Male & 8.4 & 8.1 & 1.0 & 3.0 & 6.0 & 12.0 & 18.0 \\
\hline & Female & 7.2 & 5.0 & 0.0 & 2.4 & 6.0 & 10.0 & 16.0 \\
\hline \multirow[t]{2}{*}{$55-64$ yrs } & Male & 8.7 & 8.1 & 1.0 & 2.4 & 5.0 & 13.0 & 21.0 \\
\hline & Female & 7.4 & 6.1 & 0.0 & 2.0 & 5.0 & 10.0 & 16.0 \\
\hline \multirow[t]{2}{*}{$65+$ yrs } & Male & 7.1 & 7.0 & 0.0 & 1.0 & 4.0 & 12.0 & 18.0 \\
\hline & Female & 6.0 & 6.1 & 0.0 & 1.0 & 3.5 & 8.0 & 16.0 \\
\hline
\end{tabular}

In the current study, statistically significant (but small) differences were observed between the UK and Australian dentate subjects only when we used extent and severity scores. This indicates that Australians are more likely to report adverse impacts with low frequency (ie 'occasionally' or 'hardly ever') than adults in the UK (Fig. 1). It is intriguing that the overall higher levels of physical pain and physical disability in Australia were not reflected in differences between populations in the remaining OHIP dimensions that encompass functional limitation and psychosocial disability or handicap. This apparent paradox underscores the poor understanding that is held of the processes through which individuals or populations arrive at these judgments. Perhaps Australians who experience dysfunction or discomfort are less likely to let it affect their psychological well being and social interaction than people in the UK. However, it may simply reflect a greater readiness to report minor discomfort and/or unwillingness to report severe impacts in the Australian population. The latter may constitute 'denial' which itself could be consistent with nationally held expectations. Alternatively, the relative anonymity of a mail survey, as used in Australia, may encourage disclosure of minor impacts that would not be reported in a face-to-face interview, which was the method adopted in the UK survey. In a comparison of mail, face-to-face and telephone methods for visual related quality of life, subjects reporting by mail had poorer quality of life scores than those using interview methods. ${ }^{19}$ The authors asserted that the mail survey allowed subjects to refer back to previous questions and reported that the internal consistency of items was greater in the mail survey group.

Nevertheless, subtle differences such as these can tell us quite a lot about the social and psycho-social influences on oral health impacts between populations and among sub-groups within populations. Based on results from other studies, we believe that tooth loss and socio-economic position are principal determinants of variation in oral health impact, and elsewhere we have examined effects of tooth loss in these two populations. ${ }^{20}$ However, as observed in the 2nd International Collaborative Study, we suspect that the relative contribution of those determinants and the magnitude of their effects may vary between populations and/or cultural sub-groups within populations.

1. Newman J F. Forty years of national public oral health data: continued value? J Public Health Dent. 1990; 50: 323-329.

2. Inglehart M R, Bagramian R A. Oral health-related quality of life: an introduction. In: Inglehart M R, Bagramian R A (Eds) Oral health-related quality of life. Quintessence; Carol Stream, IL, 2002: 16.

3. Locker D. Measuring oral health: a conceptual framework. Community Dent Health. 1988; 5: 3-18.

4. National Public Health Partnership Preventing Chronic Disease: A Strategic Framework - Background Paper. Melbourne, Australia; National Public Health Partnership, October 2001.

5. U.S. Department of Health and Human Services (2000). Healthy People 2010 Conference Edition, in Two Volumes. Washington, DC.

6. Chen M; Andersen R M; Barmes D E, Leclercq M-H, Lyttle, C S. Comparing oral health care systems. A second international collaborative study. Geneva: World Health Organization, 1997.

7. Slade G D. Assessment of oral health-related quality of life. In: Inglehart M R, Bagramian R A (Eds) Oral health-related quality of life. Quintessence; Carol Stream, IL, 2002: 29-46.

8. McGrath C, Bedi R. Understanding the value of oral health to people in Britain importance to life quality. Community Dent Health. 2002; 19: 211-214.

9. Slade G D. Derivation and validation of a short-form oral health impact profile Community Dent.Oral Epidemiol. 1997; 25: 284-290.

10. Kelly M, Steele J, Nuttall N, et al. Dental Health Survey - Oral Health in the United Kingdom 1998. London: The Stationery Office, 2000

11. Carter K D, Stewart J F. National Dental Telephone Interview Survey 1999. AlHW cat No. DEN 109. Adelaide: AlHW Dental Statistics and Research Unit, 2002.

12. WHO. International classification of impairments, disabilities and handicaps. Geneva: World Health Organization; 1980.

13. Slade G D, Spencer A J, Locker D, Hunt R J, Strauss R P, Beck J D. Variations in the social impact of oral conditions among older adults in South Australia, Ontario and North Carolina. J Dent Res. 1996; 75: 1439-1450.

14. Robinson P G, Gibson B, Khan FA, Birnbaum W. A comparison of OHIP 14 and OIDP as interviews and questionnaires. Community Dent Health 2001; 18: 144-149.

15. Robinson P G, Gibson B, Khan F A, Birnbaum W. Validity of two oral health-related quality of life measures. Community Dent Oral Epidemiol. 2003; 31: 90-99.

16. Locker D, Slade G D. Oral health and the quality of life among older adults: the oral health impact profile. J Can Dent Assoc. 1993; 59: 830-833, 837-838, 844.

17. Locker $D$, Miller Y. Evaluation of subjective oral health status indicators. J Public Health Dent. 1994; 54: 167-176.

18. Slade G D, Spencer A J. Social impact of oral conditions among older adults. Aust DentJ. 1994; 39: 358-364.

19. Wolffsohn J S, Cochrane A L, Watt N A. Implementation methods for vision related quality of life questionnaires. Br J Ophthalmol. 2000; 84: 1035-1040.

20. Steele J G, Sanders A E, Slade G D, Allen P F, Lahti S, Nuttall N, Spencer A J. How do age and tooth loss affect oral health impacts and quality of life? A study comparing two national samples. Community Dent Oral Epidemiol. 2004; 32: 107 -114. 